\title{
Near-Infrared Spectroscopic Assessment of Haemodynamic Activation in the Cerebral Cortex - A Review in Developmental Psychology and Child Psychiatry
}

\author{
Hitoshi Kaneko1, Toru Yoshikawa², Hiroyuki Ito ${ }^{3}$, \\ Kenji Nomura ${ }^{1}$, Takashi Okada ${ }^{2}$ and Shuji Honjo ${ }^{1}$ \\ ${ }^{1}$ Center for Developmental Clinical Psychology \\ and Psychiatry, Nagoya University \\ 2Department of Psychiatry for Parents and Children, \\ Nagoya University Hospital \\ ${ }^{3}$ Osaka-Hamamatsu Joint Center for Child Development, \\ Hamamatsu University School of Medicine
}

Japan

\section{Introduction}

This chapter aims to shed light on developmental cognitive neuroscience studies that use near-infrared spectroscopy (NIRS) to examine the cortical response in developmental psychology and child psychiatry. NIRS was first applied to the human brain in 1977 (Jöbsis, 1977) for the noninvasive measurement of the haemodynamic activation in the cerebral cortex. NIRS is advantageous over other neuroimaging methods in terms of its ease of measurement and low cost. Therefore, extensive studies have investigated neural correlates using the NIRS technique in healthy people and in neurological or psychiatric patients. Furthermore, NIRS has been applied to multiple age groups from neonates to adults. It is beyond the scope of this chapter to provide an exhaustive list of the neuroscience research based on NIRS. Here, we focus mainly on the studies that examine cognitive function from the viewpoint of developmental cognitive neuroscience.

We believe that studies on brain function in children from birth to adolescence who are healthy or have psychiatric disorders provides knowledge about the trajectory of cognitive and neural development. The advantages of NIRS over magnetoencephalography (MEG) or functional magnetic imaging (fMRI) include easy measurement and less susceptibility to signal distortion by motion artefacts (Gervain et al., 2011; Lloyd-Fox et al., 2010). Furthermore, NIRS enables the measurement of human cerebral activity in less restricted and less noisy conditions. This advantage is particularly important in studies that investigate children from infancy to adolescence. NIRS enables researchers to easily present auditory stimuli (Kaneko et al., 2011) and to conduct experiments in relatively natural social settings (Ito et al., 2011). NIRS can be performed on infants even while they sit upright on 
the lap of a parent. Therefore, NIRS is especially suited for research on children from birth to the toddler years (Lloyd-Fox et al., 2010).

\section{Techniques for assessment of brain function}

Compared to other clinical neurological methods such as electroencephalography (EEG), positron emission tomography (PET), fMRI, and MEG, NIRS was recently developed. EEG is a noninvasive method that directly measures the electrical activity of the brain via electrodes placed on the scalp. EEG has a high temporal resolution but poor spatial resolution. PET is an invasive method that uses radioactive tracers to measure the metabolism of the brain. PET provides high specific spatial resolution but poor temporal resolution. fMRI is a noninvasive method that measures the changes in blood oxygenation, and provides good spatial resolution but limited temporal resolution. MEG is a noninvasive method that measures the magnetic fields induced by electrical activity in the brain. MEG has good spatial and temporal resolution; however, MEG also requires the participants to remain very still during measurement.

NIRS is completely noninvasive, more patient-friendly, and can be performed very easily compared to other neurological techniques. It is relatively inexpensive compared to fMRI, making it possible to measure haemodynamic changes at a low cost. Furthermore, the NIRS instrument is portable; measurements can be obtained in situ, for example, at the bedside. In addition, the NIRS probe for assessing brain activity is very flexible, and does not require the patient to be still or maintain the head in any particular position (Minagawa-Kawai et al., 2008). These attributes are especially useful when the patients are children, as it enables them to feel relaxed even in an experimental setting. FMRI and MEG studies are difficult to perform in children, because these techniques require the patients to be still. Most fMRI studies in infants have been performed while they are asleep or are sedated inside the imaging tunnel (Lloyd-Fox et al., 2010; Minagawa-Kawai et al., 2008).

NIRS has a higher temporal resolution than fMRI. Haemodynamic changes at $10 \mathrm{~Hz}$ can be measured with commercially available products, whereas a typical fMRI instrument provides a temporal resolution of a few seconds. NIRS provides the concentration changes in both oxy-haemoglobin and deoxy-haemoglobin, whereas fMRI measures only deoxyhaemoglobin. NIRS is not as noisy as fMRI, and the NIRS signal is less affected by motion artefacts compared to signals of fMRI or MEG. Additionally, NIRS permits continuous and repeated measurement.

However, one limitation of NIRS is that it assesses brain function indirectly by measuring the haemodynamic changes in haemoglobin via an optical fibre probe attached to the scalp. The working principle of NIRS is that neural activation requires oxygen consumption; therefore, the haemoglobin concentration in the blood vessels depends on the neural activity. EEG, in contrast, assesses brain function directly by measuring the electrical potential of neurons via electrodes attached to the scalp. Additionally, although NIRS assesses brain activity via haemodynamic changes in the cerebral cortex, it is unable to examine deep brain activation. Specifically, NIRS allows the assessment of haemoglobin concentrations up to only 2 or $3 \mathrm{~cm}$ below the skull; therefore, the activation in the deep brain regions cannot be measured. Furthermore, NIRS has a low spatial resolution compared to fMRI or MEG; the spatial resolution of NIRS is $20-30 \mathrm{~mm}$, whereas that of $\mathrm{fMRI}$ is $1-2 \mathrm{~mm}$. 


\section{NIRS: Principles and methods in the assessment of the human cerebral cortex}

Biological tissue is relatively transparent to light in the near-infrared range. In NIRS, light at wavelengths of 700-900 $\mathrm{nm}$ is illuminated onto the scalp. Oxy-haemoglobin and deoxyhaemoglobin chromophores have different absorption spectra that are used to assess the attenuated light levels via changes in the chromophore concentration; these concentration changes can be used to determine the haemodynamic response.

Because oxygen consumption increases in the region of the brain with the greatest activity, changes in the oxygen content of the blood can be used to measure the relative levels of brain activity. The specific parameters of the response monitored with NIRS represent changes in the levels of oxygenated and deoxygenated haemoglobin at specific regions across the cerebral cortex during stimulation. The detailed principles of NIRS have been described previously (e.g. Gervain et al., 2011; Hoshi, 2007; Minagawa-Kawai et al., 2008; Strangman et al., 2002).

\section{Applications in developmental psychology}

\subsection{Functional brain activity in infants}

After Jöbsis first applied NIRS to the human brain (Jöbsis, 1977), there has been an increasing interest in measuring the haemodynamic response in the cerebral cortex of humans, especially in neonatal patients in the neonatal intensive care unit (NICU). NIRS is especially suitable for studies in neonates and is increasingly used in high-risk neonates, including low-birth-weight infants, neonates with congenital heart defects, and neonates with other pathological states (Goff et al., 2010; Wyatt et al., 1986). The neonatal skull is thinner than that of adults; therefore, near-infrared light can penetrate deeper into the neonatal cortex than into the adult cortex. The first study to use NIRS to evaluate cerebral oxygenation saturation in pre-term infants was published in 1985 (Brazy et al., 1985). Subsequently, extensive research has revealed that NIRS is highly effective for monitoring cerebral oxygenation saturation in the NICU (Brazy et al., 1985).

Although numerous studies have demonstrated that NIRS is valuable for the assessment of neonates in the NICU, the use of NIRS in measuring cognitive function in infants has not been fully investigated. Early NIRS studies examined infants who were presented with stimuli while they were asleep (Aoyama et al., 2010; Homae et al., 2007; Saito et al., 2007a, 2007b, 2009).

Over the last decade, NIRS has been successfully applied to awake infants in experimental settings (Homae et al., 2010; Hyde et al., 2010; Nakano et al., 2009; Taga et al., 2003; Taga \& Asakawa, 2007; Watanabe et al., 2010; Wilcox et al., 2008, 2009, 2010). Figure 1 shows an experimental setting where infants can sit upright on the lap of a parent wearing NIRS probes and headgear designed for infants.

In the next section, we address the neural activation during face recognition in infants. Face recognition is important for infants and adults, because the face represents not only the personal identity but also the emotional expressions of an individual. In social communication, it is essential to understand the thoughts of a person via their facial expressions. Although many event rerated potential (ERP) studies in infants have examined 


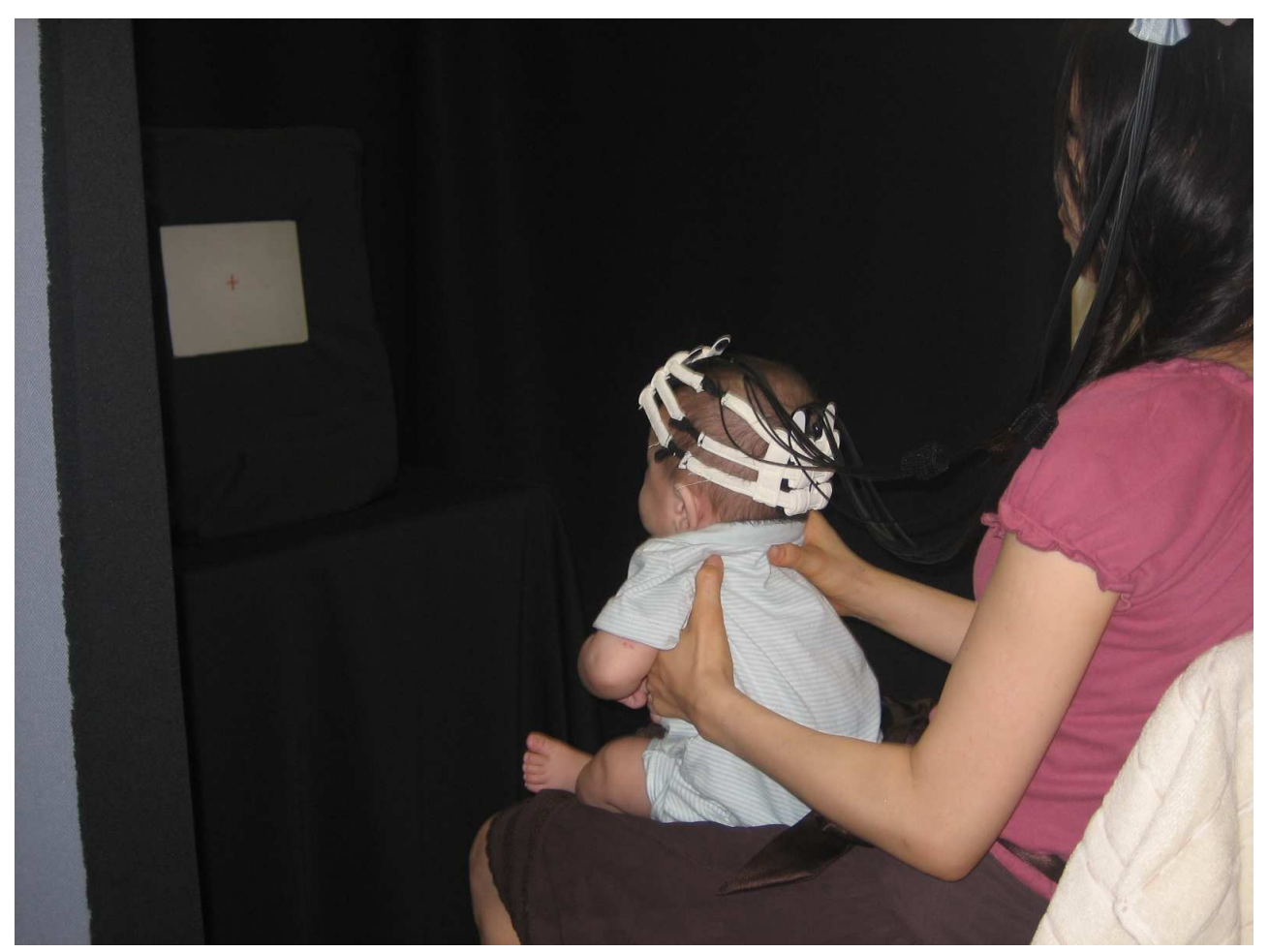

Fig. 1. Experimental setting using NIRS for awake infants

the neural substrates of facial recognition (de Haan et al., 2003), relatively few NIRS studies have been documented. However, NIRS has been applied to other research areas such as cerebral lateralization and speech acquisition (Minagawa-Kawai et al., 2008).

\subsection{Haemodynamic responses in infants during face recognition}

Haemodynamic changes during the face recognition process as assessed by NIRS have been documented in several studies (Blasi et al., 2007; Csibra et al., 2004; Grossmann et al., 2008; Honda et al., 2010; Ichikawa et al., 2010; Nakato et al., 2009, 2011a, 2011b; Otsuka et al., 2007). Newborns showed a spontaneous preference for face-like stimuli over non-face-like patterns (Fantz, 1961). It is crucial for infants to discriminate the face of their caregiver face from the faces of other persons to elicit care. The ability to recognise emotion in facial expressions is also important for infants to communicate effectively to caregivers, and this represents the emergence of social communication. Numerous behavioural and electrophysiological studies have demonstrated that 5-7-month-old infants can visibly discriminate different facial expressions and exhibit an attention bias towards salient facial expressions (Leppanen \& Nelson, 2009). Recent NIRS studies have demonstrated that infants show different haemodynamic responses to different facial stimuli (Nakato et al., 2009, 2011a, 2011b). 
Infants respond to happy faces and angry faces with distinct haemodynamic changes in their cortical regions (Nakato et al., 2011b). Nakato et al. found that the left temporal region, particularly the left superior temporal sulcus, was significantly activated in response to happy faces, whereas the right temporal region was activated in response to angry faces. Furthermore, happy faces increased the haemodynamic response gradually, and the response was maintained even after the happy face stimuli disappeared. In contrast, when angry face stimuli were presented, the haemodynamic response peaked quickly and decreased more rapidly after the angry faces disappeared.

The infants' response to their mother's face and to the faces of unfamiliar women was also accompanied by haemodynamic changes in the cortical regions (Nakato et al., 2011a). In response to the mother's face, the oxy- $\mathrm{Hb}$ and total- $\mathrm{Hb}$ concentrations increased in the right and left temporal cortices. In contrast, in response to the faces of unfamiliar women, no activation was observed in the left temporal cortex, although the total-haemoglobin concentration in the right temporal cortex was increased.

Moreover, infants have shown developmental changes in haemodynamic activity during the recognition of faces in frontal view and profile view (Nakato et al., 2009). The oxyhaemoglobin and total-haemoglobin concentrations in 5-month-old infants only increased for the frontal view in the right temporal regions. However, the oxy-haemoglobin and total-haemoglobin concentrations in 8-month-old infants increased for both frontal and profile views. These studies suggest that the right temporal hemisphere is specialised for face recognition in infants (Carlsson et al., 2008; Nakato et al., 2011; Nakato et al., 2009; Otsuka et al., 2007). Previous neuroimaging studies in adults also indicated that the right temporal cortex is involved in face recognition. Thus, it is suggested that the components of the facial recognition system that adults possess emerge as precursors in the early infant periods.

Although accumulating evidence indicates that infants respond to face stimuli differently in terms of the haemodynamic changes in the temporal cortex, other brain areas, e.g. the fusiform face area and lateral occipital cortex, have not been fully investigated. The fusiform face area is considered to play a crucial role in face perception, especially in face identification (Johnson, 2005; Kanwisher \& Yovel, 2006; Tsao \& Livingstone, 2008). However, the fusiform face area is deeply located, and hence, its activity cannot be measured by NIRS. The orbitofrontal cortex and amygdala areas of that have been implicated in the recognition of the emotions of facial expressions (Leppanen \& Nelson, 2009).

\subsection{Neural basis of infant-mother attachment}

Infant-mother attachment is essential for the development of infants. Infants use attachment behaviours to deepen the intimacy with their caregiver, thereby eliciting ample care from their caregiver and increasing their prospect for surviving. Many researchers have investigated the attachment behaviour of infants in developmental psychology; however, few studies have investigated the neural substrates of infant-mother attachment. fMRI studies have indicated that the brains of mothers are more activated by their own infants than by other infants stimuli (Kim et al., 2011; Lenzi et al., 2009; Noriuchi et al., 2008). Noriuchi et al. found that the right orbitofrontal cortex, periaqueductal gray, anterior insula, 
and dorsal and ventrolateral putamen of mothers responded more positively to video clips of their own infants than to clips of unfamiliar infants (Noriuchi et al., 2008).

In contrast, surprisingly, little research is available about the neural correlates of infant brain activity associated with infant-mother attachment. Recently, using NIRS for awake infants, Minagawa-kawai et al. found that infants showed greater activation in the orbitofrontal cortex when they were presented with movie clips in which their own mothers smiled (Minagawa-Kawai et al., 2009).

Additionally, an fMRI study on adults revealed that the orbitofrontal cortex is activated by attractive faces (O'Doherty et al., 2003; Tsukiura \& Cabeza, 2011). Similarly, the orbitofrontal cortex has been shown to have various functions, such as social cognition, motivational evaluation, emotional processing, and decision-making (Adolphs, 2003; Kringelbach, 2005).

Infant-mother attachment underpins the basis for life-long interpersonal relationships. Infants begin their life with affectionate social interactions with their mothers immediately after delivery. Many studies have shown that social interaction with caregivers is essential for healthy development in children (e.g. Smyke et al, 2007). However, little is known about how the brains of children develop continually until adulthood through social interaction with caregivers.

Face-to-face communication between mothers and infants is highly complicated, and is affected by many confounding variables, such as face expression, pitch of speech, and contingency of turn-taking. Therefore, it is technically difficult in experimental paradigms to examine the effects of face-to-face communication of mothers and infants. Further research is required to improve experimental paradigms that better approximate real life (Grossmann \& Johnson, 2007) and to examine effects of face-to-face communication with the mother on the development of the brain of the infant.

\subsection{Cognitive development in preschool children}

In contrast to infant studies, studies on cognitive development in preschool children have largely not used neuroimaging methods. However, several studies have examined haemodynamic changes of the cerebral cortex using NIRS during cognitive shifting (Moriguchi \& Hiraki, 2009, 2011) or working memory tasks (Tsujii et al., 2009, 2010; Tsujimoto et al., 2004).

Moriguchi \& Hiraki (2009) found that 3-year-old children who committed perseverative errors lacked activation in their inferior prefrontal regions during cognitive shifting tasks, whereas those who performed the tasks correctly displayed activation of the right inferior prefrontal regions. Furthermore, a longitudinal study of prefrontal function in 3-4-year-old children showed that children who performed better tasks at 3 years of age showed significant activation of the right inferior prefrontal regions at 3 years of age, and significant activation of the both inferior prefrontal regions at 4 years of age (Moriguchi \& Hiraki, 2011). Children who showed poorer performance at 3 years of age exhibited no significant inferior prefrontal activation at 3 years of age, but significant left inferior prefrontal activation at 4 years of age. It was therefore suggested that inferior prefrontal activation on either the right or left side may be more important for successful cognitive shifting than 
sustained right inferior prefrontal activation. Moreover, multiple patterns of prefrontal activation were observed during the cognitive shifting tasks.

Tsujimoto et al. (2004) examined the cortical response of preschool children aged 5-6 years during spatial working memory tasks and found that the oxy-haemoglobin concentration was increased in the lateral prefrontal cortex, which is associated with working memory processes in adults. In another research group, Tusjii et al. found that the frontal activation was greater in 5-year-old children than in 7-year-old children during a spatial working memory task (Tsujii et al., 2009). Furthermore, right hemisphere dominance was observed in older children, but no significant hemispheric differences were observed in younger children. Children with strong lateralization showed improved performance from 5 to 7 years of age. These findings suggest that right lateralization for spatial working memory may start between 5 and 7 years of age.

Although NIRS is better suited for use in preschool children compared to other neuroimaging methods, brain function in preschool children measured by NIRS has not been well-documented. Numerous investigations have examined various aspects of brain function in human adults using fMRI or MEG. However, to date, no studies have addressed how the human brain develops and organises diverse cognitive ability from birth to adulthood. Further research needs to elucidate the development of brain function in preschool children.

\section{Applications in child psychiatry}

\subsection{Brain dysfunction in children with autism spectrum disorders}

Autism spectrum disorders (ASDs), including autistic disorder and Asperger disorder, are diagnosed by cataloguing behavioural features including the impairment of reciprocal social interaction and communication, as well as the presence of repetitive ritualistic behaviour or interests. Methodological differences make it difficult to compare epidemiological studies; therefore, there are discrepancies in the reported prevalence of ASDs. However, the prevalence of ASDs has been conservatively estimated at 36.4/10,000 (Fombonne, 2005). The severity of impairment varies greatly among patients, and they occasionally show mental retardation. The impairment is evident at least prior to the age of 3 years, and its effects persist life-long.

ASDs are characterised by pervasive impairments in social behaviour. Accumulating evidence suggests that adults with ASDs have altered brain activity in regions related to social interactions (Neuhaus et al., 2010), such as the superior temporal gyrus (Meresse et al., 2005), fusiform gyrus (Koshino et al., 2008), amygdala (Pinkham et al., 2008), and prefrontal cortex (Gilbert et al., 2009). Although previous studies have elucidated that adults with ASDs show reduced or altered activation in the aforementioned regions compared with healthy adults, surprisingly, little neuroimaging data are available for autistic children.

Kawakubo et al. examined prefrontal haemodynamic activation during a verbal fluency task in children and adults with ASDs (Kawakubo et al., 2009). In children, there were no significant differences in the haemodynamic changes between patients with ASDs and healthy controls. However, the concentration of oxy-haemoglobin in adults with ASDs was 
significantly lower than that in healthy controls. These findings suggest that developmental changes in prefrontal activity of individuals with ASDs emerge before adulthood, i.e. they appear during adolescence.

\subsection{Brain dysfunction in children with attention-deficit hyperactivity disorder}

Attention-deficit hyperactivity disorder (ADHD) is a neurodevelopmental disorder whose prevalence has been estimated to be $3 \%$ to $7 \%$ of school-age children (American Psychiatric Association [APA], 2000). The essential clinical symptoms include inattention and/or hyperactivity-impulsivity. Some hyperactive-impulsive or inattentive symptoms must be present before the age of 7 years, although some symptoms that cause impairment tend to persist life-long. Some impairment from the symptoms is typically evident at school and at home, with behaviour that is clearly inappropriate for the developmental age in social, academic, or occupational settings.

In particular, ADHD is characterised by impairments in executive function, i.e. the failure of inhibitory control and the dysregulation of brain systems mediating reward and response (Sonuga-Barke, 2003). The Go/NoGo task, stop-signal task, and Stroop colourword task have been used to investigate the inhibition process in these patients. Some studies have examined brain function in ADHD children during the Stroop colour-word task using NIRS. Moser et al. examined the brain activation in the dorsolateral prefrontal cortex (Moser et al., 2009), and showed that the oxy-haemoglobin concentration peaked later in ADHD children than in healthy children. Additionally, the concentration of deoxy-haemoglobin increased just after the onset of stimulation in ADHD children but decreased in healthy children. Negoro et al. examined the activation of frontal regions in the brain using 24-channel NIRS during the Stroop colour-word task (Negoro et al., 2010), and showed that the concentration of oxy-haemoglobin in the inferior prefrontal cortex in ADHD children decreased compared with that in healthy children, especially in the both the inferior lateral prefrontal cortex.

The trail-making test, which assesses executive function, has been used for the measurement of brain activation in ADHD children. Weber et al. showed that the concentration of oxyhaemoglobin increased in ADHD children during the short attention phase, whereas no significant change was observed in healthy children (Weber et al., 2005). A significant increase in oxy-haemoglobin was also reported for both groups during the extended attention phase, although an additional increase was observed in deoxy-haemoglobin level only in the healthy children.

These findings suggest that during tasks involving executive function, the haemodynamic responses in ADHD children are different from those in healthy children.

\section{Conclusions}

NIRS can greatly aid in extending our existing experimental paradigms. With NIRS, we can measure haemodynamic changes in the cerebral cortex of children, and accumulate more information on brain activity from infancy to adolescence. Such information is of great importance in studying brain function from a developmental perspective. However, surprisingly, the available research, even on topics like the typical trajectory of functional brain development, is less. 
Furthermore, research on atypical brain function in ASDs or ADHD is needed to clarify the differences between typical and atypical functional brain development. The understanding of brain function in children with psychiatric disorders is key to developing effective intervention methods. For early intervention, we need to elucidate the process of cognitive neurodevelopment in the early stages of development. Thus, NIRS is a valuable modality for monitoring and investigating brain activity in children with psychiatric disorders.

\section{References}

Adolphs, R. (2003). Cognitive neuroscience of human social behaviour. Nature Reviews Neuroscience, Vol.4, pp.165-178, ISSN 1471-0048

Aoyama, S., Toshima, T., Saito, Y., Konishi, N., Motoshige, K., Ishikawa, N., Nakamura, K., \& Kobayashi, M. (2010). Maternal breast milk odour induces frontal lobe activation in neonates: A NIRS study. Early Human Development, Vol.86, pp.541-545, ISSN 0378-3782

American Psychiatric Association. (2000). Diagnostic and Statistical Manual of Mental Disorders, Fourth Edition, Text Revision (DSM-IV-TR). American Psychiatric Association, ISBN 0-89042-025-4 Arlington, VA

Blasi, A., Fox, S., Everdell, N., Volein, A., Tucker, L., Csibra, G., Gibson, A. P., Hebden, J. C., Johnson, M. H., \& Elwell, C. E. (2007). Investigation of depth dependent changes in cerebral haemodynamics during face perception in infants. Physics in Medicine and Biology, Vol.52, pp.6849-6864, ISSN 0031-9155

Brazy, J. E., Lewis, D. V., Mitnick, M. H., \& Vandervliet, F. F. J. (1985). Noninvasive Monitoring of cerebral oxygenation in preterm infants: Preliminary observations. Pediatrics, Vol.75, pp.217-225, ISSN 0031-4005

Carlsson, J., Lagercrantz, H., Olson, L., Printz, G., \& Bartocci, M. (2008). Activation of the right fronto-temporal cortex during maternal facial recognition in young infants. Acta Paediatrica, Vol.97, pp.1221-1225, ISSN 0803-5253

Csibra., G., Henty., J., Volein., Á., Elwell., C., Tucker., L., Meek., J., \& Johnson., M. H. (2004). Near infrared spectroscopy reveals neural activation during face perception in infants and adults. Journal of pediatric neurology, Vol.2, pp.85-89, ISSN 1304-2580

de Haan, M., Johnson, M. H., \& Halit, H. (2003). Development of face-sensitive event-related potentials during infancy: a review. International Journal of Psychophysiology, Vol.51, pp.45-58, ISSN 0167-8760

Fantz, R. L. (1961). The origin of form perception. Scientific American, Vol.204, pp.66-72, ISSN 0036-8733

Fombonne, E. (2005). Epidemiological surveys of pervasive developmental disorders, In: Autism and pervasive developmental disorders. Volkmar, F. R., Paul, R., Klin A., \& Cohen D. pp.42-69, Cambridge University Press. ISBN 0-471-71696-0, New York. USA

Gervain, J., Mehler, J., Werker, J. F., Nelson, C. A., Csibra, G., Lloyd-Fox, S., Shukla, M., \& Aslin, R. N. (2011). Near-infrared spectroscopy: A report from the McDonnell infant methodology consortium. Developmental Cognitive Neuroscience, Vol.1, pp.2246, ISSN 1878-9293 
Gilbert, S. J., Meuwese, J. D. I., Towgood, K. J., Frith, C. D., \& Burgess, P. W. (2009). Abnormal functional specialization within medial prefrontal cortex in highfunctioning autism: a multi-voxel similarity analysis. Brain, Vol.132, pp.869-878, ISSN 0006-8950

Goff, D. A., Buckley, E. M., Durduran, T., Wang, J., \& Licht, D. J. (2010). Noninvasive cerebral perfusion imaging in high-risk neonates. Seminars in Perinatology, Vol.34, pp.46-56, ISSN 0146-0005

Grossmann, T., \& Johnson, M. H. (2007). The development of the social brain in human infancy. European Journal of Neuroscience, Vol.25, pp.909-919, ISSN 0953-816X

Grossmann, T., Johnson, M. H., Lloyd-Fox, S., Blasi, A., Deligianni, F., Elwell, C., \& Csibra, G. (2008). Early cortical specialization for face-to-face communication in human infants. Proceedings of the Royal Society B-Biological Sciences, Vol.275, pp.2803-2811, ISSN 0962-8452

Homae, F., Watanabe, H., Nakano, T., \& Taga, G. (2007). Prosodic processing in the developing brain. Neuroscience Research, Vol.59, pp.29-39, ISSN 0168-0102

Homae, F., Watanabe, H., Otobe, T., Nakano, T., Go, T., Konishi, Y., \& Taga, G. (2010). Development of global cortical networks in early infancy. Journal of Neuroscience, Vol.30, pp.4877-4882, ISSN 1529-2401

Honda, Y., Nakato, E., Otsuka, Y., Kanazawa, S., Kojima, S., Yamaguchi, M. K., \& Kakigi, R. (2010). How do infants perceive scrambled face?: A near-infrared spectroscopic study. Brain Research, Vol.1308, pp.137-146, ISSN 0006-8993

Hoshi, Y. (2007). Functional near-infrared spectroscopy: Current status and future prospects. Journal of Biomedical Optics, Vol.12, pp.062106-1-062106-9, ISSN 1083-3668

Hyde, D. C., Boas, D. A., Blair, C., \& Carey, S. (2010). Near-infrared spectroscopy shows right parietal specialization for number in pre-verbal infants. Neuroimage, Vol.53, pp.647-652, ISSN 1053-8119

Ichikawa, H., Kanazawa, S., Yamaguchi, M. K., \& Kakigi, R. (2010). Infant brain activity while viewing facial movement of point-light displays as measured by nearinfrared spectroscopy (NIRS). Neuroscience Letters, Vol.482, pp.90-94, ISSN 03043940

Ito, H., Yamauchi, H., Kaneko, H., Yoshikawa, T., Nomura, K., \& Honjo, S. (2011). Prefrontal overactivation, autonomic arousal, and task performance under evaluative pressure: A near-infrared spectroscopy (NIRS) study. Psychophysiology, pp.15631571, ISSN 1469-8986

Jöbsis, F. F. (1977). Noninvasive, infrared monitoring of cerebral and myocardial oxygen sufficiency and circulatory parameters. Science, Vol.198, pp.1264-1267, ISSN 00368075

Johnson, M. H. (2005). Subcortical face processing. Nature Reviews Neuroscience, Vol.6, pp.766-774, ISSN 1471-0048

Kaneko, H., Yoshikawa, T., Nomura, K., Ito, H., Yamauchi, H., Ogura, M., \& Honjo, S. (2011). Hemodynamic changes in the prefrontal cortex during digit span task: A near-infrared spectroscopy study. Neuropsychobiology, Vol.63, pp.59-65, ISSN 0302$282 X$

Kanwisher, N., \& Yovel, G. (2006). The fusiform face area: a cortical region specialized for the perception of faces. Philosophical Transactions of the Royal Society B-Biological Sciences, Vol.361, pp.2109-2128, ISSN 0962-8436 
Kawakubo, Y., Kuwabara, H., Watanabe, K., Minowa, M., Someya, T., Minowa, I., Kono, T., Nishida, H., Sugiyama, T., Kato, N., \& Kasai, K. (2009). Impaired prefrontal hemodynamic maturation in autism and unaffected siblings. PLoS One, Vol.4, ISSN 1932-6203

Kim, P., Feldman, R., Mayes, L. C., Eicher, V., Thompson, N., Leckman, J. F., \& Swain, J. E. (2011). Breastfeeding, brain activation to own infant cry, and maternal sensitivity. Journal of Child Psychology and Psychiatry, Vol.52, pp.907-915, ISSN 0021-9630

Koshino, H., Kana, R. K., Keller, T. A., Cherkassky, V. L., Minshew, N. J., \& Just, M. A. (2008). fMRI investigation of working memory for faces in autism: Visual coding and underconnectivity with frontal areas. Cerebral Cortex, Vol.18, pp.289-300, ISSN 1047-3211

Kringelbach, M. L. (2005). The human orbitofrontal cortex: Linking reward to hedonic experience. Nature Reviews Neuroscience, Vol.6, pp.691-702, ISSN 1471-0048

Lenzi, D., Trentini, C., Pantano, P., Macaluso, E., Iacoboni, M., Lenzi, G. L., \& Ammaniti, M. (2009). Neural basis of maternal communication and emotional expression processing during infant preverbal stage. Cerebral Cortex, Vol.19, pp.1124-1133, ISSN 1047-3211

Leppanen, J. M., \& Nelson, C. A. (2009). Tuning the developing brain to social signals of emotions. Nature Reviews Neuroscience, Vol.10, pp.37-47, ISSN 1471-0048

Lloyd-Fox, S., Blasi, A., \& Elwell, C. E. (2010). Illuminating the developing brain: The past, present and future of functional near infrared spectroscopy. Neuroscience and Biobehavioral Reviews, Vol.34, pp.269-284, ISSN 0149-7634

Meresse, I. G., Zilbovicius, M., Boddaert, N., Robel, L., Philippe, A., Sfaello, I., Laurier, L., Brunelle, F., Samson, Y., Mouren, M. C., \& Chabane, N. (2005). Autism severity and temporal lobe functional abnormalities. Annals of Neurology, Vol.58, pp.466-469, ISSN 0364-5134

Minagawa-Kawai, Y., Matsuoka, S., Dan, I., Naoi, N., Nakamura, K., \& Kojima, S. (2009). prefrontal activation associated with social attachment: Facial-emotion recognition in mothers and infants. Cerebral Cortex, Vol.19, pp.284-292, ISSN 1047-3211

Minagawa-Kawai, Y., Mori, K., Hebden, J. C., \& Dupoux, E. (2008). Optical Imaging of infants' neurocognitive development: Recent advances and perspectives. Developmental Neurobiology, Vol.68, pp.712-728, ISSN 1932-8451

Moriguchi, Y., \& Hiraki, K. (2009). Neural origin of cognitive shifting in young children. Proceedings of the National Academy of Sciences of the United States of America, Vol.106, pp.6017-6021, ISSN 0027-8424

Moriguchi, Y., \& Hiraki, K. (2011). Longitudinal development of prefrontal function during early childhood. Developmental Cognitive Neuroscience, Vol.1, pp.153-162, ISSN 18789293

Moser, S. J., Schroeter, M. L., Cutini, S., \& Weber, P. (2009). Right prefrontal brain activation due to Stroop interference is altered in attention-deficit hyperactivity disorder - A functional near-infrared spectroscopy study. Psychiatry Research-Neuroimaging, Vol.173, pp.190-195, ISSN 0925-4927

Nakano, T., Watanabe, H., Homae, F., \& Taga, G. (2009). Prefrontal cortical involvement in young infants' analysis of novelty. Cerebral Cortex, Vol.19, pp.455-463, ISSN 10473211 
Nakato, E., Otsuka, Y., Kanazawa, S., Yamaguchi, M. K., Honda, Y., \& Kakigi, R. (2011a). I know this face: Neural activity during mother' face perception in 7- to 8-month-old infants as investigated by near-infrared spectroscopy. Early Human Development, Vol.87, pp.1-7, ISSN 0378-3782

Nakato, E., Otsuka, Y., Kanazawa, S., Yamaguchi, M. K., \& Kakigi, R. (2011b). Distinct differences in the pattern of hemodynamic response to happy and angry facial expressions in infants - A near-infrared spectroscopic study. Neuroimage, Vol.54, pp.1600-1606, ISSN 1053-8119

Nakato, E., Otsuka, Y., Kanazawa, S., Yamaguchi, M. K., Watanabe, S., \& Kakigi, R. (2009). When do infants differentiate profile face from frontal face? A near-infrared spectroscopic study. Human Brain Mapping, Vol.30, pp.462-472, ISSN 1065-9471

Negoro, H., Sawada, M., Iida, J., Ota, T., Tanaka, S., \& Kishimoto, T. (2010). Prefrontal dysfunction in attention-deficit/hyperactivity disorder as measured by nearinfrared spectroscopy. Child Psychiatry and Human Development, Vol.41, pp.193-203, ISSN 0009-398X

Neuhaus, E., Beauchaine, T. P., \& Bernier, R. (2010). Neurobiological correlates of social functioning in autism. Clinical Psychology Review, Vol.30, pp.733-748, ISSN 02727358

Noriuchi, M., Kikuchi, Y., \& Senoo, A. (2008). The functional neuroanatomy of maternal love: Mother's response to infant's attachment behaviors. Biological Psychiatry, Vol.63, pp.415-423, ISSN 0006-3223

O'Doherty, J., Winston, J., Critchley, H., Perrett, D., Burt, D. M., \& Dolan, R. J. (2003). Beauty in a smile: the role of medial orbitofrontal cortex in facial attractiveness. Neuropsychologia, Vol.41, pp.147-155, ISSN 0028-3932

Otsuka, Y., Nakato, E., Kanazawa, S., Yamaguchi, M. K., Watanabe, S., \& Kakigi, R. (2007). Neural activation to upright and inverted faces in infants measured by near infrared spectroscopy. Neuroimage, Vol.34, pp.399-406, ISSN 1053-8119

Pinkham, A. E., Hopfinger, J. B., Pelphrey, K. A., Piven, J., \& Penn, D. L. (2008). Neural bases for impaired social cognition in schizophrenia and autism spectrum disorders. Schizophrenia Research, Vol.99, pp.164-175, ISSN 0920-9964

Saito, Y., Aoyama, S., Kondo, T., Fukumoto, R., Konishi, N., Nakamura, K., Kobayashi, M., \& Toshima, T. (2007). Frontal cerebral blood flow change associated with infantdirected speech. Archives of Disease in Childhood-Fetal and Neonatal Edition, Vol.92, pp.F113-F116, ISSN 1359-2998

Saito, Y., Fukuhara, R., Aoyama, S., \& Toshima, T. (2009). Frontal brain activation in premature infants' response to auditory stimuli in neonatal intensive care unit. Early Human Development, Vol.85, pp.471-474, ISSN 0378-3782

Saito, Y., Kondo, T., Aoyama, S., Fukumoto, R., Konishi, N., Nakamura, K., Kobayashi, M., \& Toshima, T. (2007). The function of the frontal lobe in neonates for response to a prosodic voice. Early Human Development, Vol.83, pp.225-230, ISSN 0378-3782

Smyke, A. T., Koga, S. F., Johnson, D. E., Fox, N. A., Marshall, P. J., Nelson, C. A., Zeanah, C. H., \& Grp, B. C. (2007). The caregiving context in institution-reared and familyreared infants and toddlers in Romania. Journal of Child Psychology and Psychiatry, Vol.48, pp.210-218, ISSN 0021-9630 
Sonuga-Barke, E. J. (2003). The dual pathway model of AD/HD: an elaboration of neurodevelopmental characteristics. Neuroscience \& Biobehavioral Reviews, Vol.27, pp.593604, ISSN 0149-7634

Strangman, G., Boas, D. A., \& Sutton, J. P. (2002). Non-invasive neuroimaging using nearinfrared light. Biological Psychiatry, Vol.52, pp.679-693, ISSN 0006-3223

Taga, G., \& Asakawa, K. (2007). Selectivity and localization of cortical response to auditory and visual stimulation in awake infants aged 2 to 4 months. Neuroimage, Vol.36, pp.1246-1252, ISSN 1053-8119

Taga, G., Asakawa, K., Maki, A., Konishi, Y., \& Koizumi, H. (2003). Brain imaging in awake infants by near-infrared optical topography. Proceedings of the National Academy of Sciences of the United States of America, Vol.100, pp.10722-10727, ISSN 0027-8424

Tsao, D. Y., \& Livingstone, M. S. (2008). Mechanisms of face perception Annual Review of Neuroscience Vol. 31, pp. 411-437, ISSN 0147-006X

Tsujii, T., Yamamoto, E., Masuda, S., \& Watanabe, S. (2009). Longitudinal study of spatial working memory development in young children. Neuroreport, Vol.20, pp.759-763, ISSN 0959-4965

Tsujii, T., Yamamoto, E., Ohira, T., Takahashi, T., \& Watanabe, S. (2010). Antihistamine effects on prefrontal cortex activity during working memory process in preschool children: A near-infrared spectroscopy (NIRS) study. Neuroscience Research, Vol.67, pp.80-85, ISSN 0168-0102

Tsujimoto, S., Yamamoto, T., Kawaguchi, H., Koizumi, H., \& Sawaguchi, T. (2004). Prefrontal cortical activation associated with working memory in adults and preschool children: An event-related optical topography study. Cerebral Cortex, Vol.14, pp.703-712, ISSN 1047-3211

Tsukiura, T., \& Cabeza, R. (2011). Remembering beauty: Roles of orbitofrontal and hippocampal regions in successful memory encoding of attractive faces. Neuroimage, Vol.54, pp.653-660, ISSN 1053-8119

Watanabe, H., Homae, F., \& Taga, G. (2010). General to specific development of functional activation in the cerebral cortexes of 2- to 3-month-old infants. Neuroimage, Vol.50, pp.1536-1544, ISSN 1053-8119

Weber, P., Lutschg, J., \& Fahnenstich, H. (2005). Cerebral hemodynamic changes in response to an executive function task in children with attention-deficit hyperactivity disorder measured by near-infrared spectroscopy. Journal of Developmental and Behavioral Pediatrics, Vol.26, pp.105-111, ISSN 0196-206X

Wilcox, T., Bortfeld, H., Woods, R., Wruck, E., Armstrong, J., \& Boas, D. (2009). Hemodynamic changes in the infant cortex during the processing of featural and spatiotemporal information. Neuropsychologia, Vol.47, pp.657-662, ISSN 0028-3932

Wilcox, T., Bortfeld, H., Woods, R., Wruck, E., \& Boas, D. A. (2008). Hemodynamic response to featural changes in the occipital and inferior temporal cortex in infants: a preliminary methodological exploration. Developmental Science, Vol.11, pp.361-370, ISSN 1363-755X

Wilcox, T., Haslup, J. A., \& Boas, D. A. (2010). Dissociation of processing of featural and spatiotemporal information in the infant cortex. Neuroimage, Vol.53, pp.1256-1263, ISSN 1053-8119 
Wyatt, J. S., Delpy, D. T., Cope, M., Wray, S., \& Reynolds, E. O. R. (1986). Quantification of Cerebral oxygenation and hemodynamics in sick newborn-infants infrared spectrophotometry. Lancet, Vol.2, pp.1063-1066, ISSN 0140-6736 


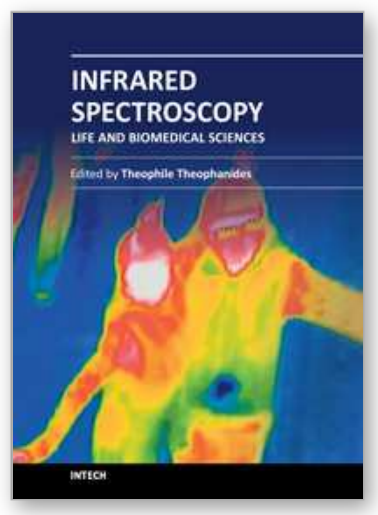

\author{
Infrared Spectroscopy - Life and Biomedical Sciences \\ Edited by Prof. Theophanides Theophile
}

ISBN 978-953-51-0538-1

Hard cover, 368 pages

Publisher InTech

Published online 25, April, 2012

Published in print edition April, 2012

This informative and state-of-the art book on Infrared Spectroscopy in Life sciences designed for researchers, academics as well as for those working in industry, agriculture and in pharmaceutical companies features 20 chapters of applications of MIRS and NIRS in brain activity and clinical research. It shows excellent FT-IR spectra of breast tissues, atheromatic plaques, human bones and projects assessment of haemodynamic activation in the cerebral cortex, brain oxygenation studies and many interesting insights from a medical perspective.

\title{
How to reference
}

In order to correctly reference this scholarly work, feel free to copy and paste the following:

Hitoshi Kaneko, Toru Yoshikawa, Hiroyuki Ito, Kenji Nomura, Takashi Okada and Shuji Honjo (2012). NearInfrared Spectroscopic Assessment of Haemodynamic Activation in the Cerebral Cortex - A Review in Developmental Psychology and Child Psychiatry, Infrared Spectroscopy - Life and Biomedical Sciences, Prof. Theophanides Theophile (Ed.), ISBN: 978-953-51-0538-1, InTech, Available from:

http://www.intechopen.com/books/infrared-spectroscopy-life-and-biomedical-sciences/near-infraredspectroscopic-assessment-of-haemodynamic-activation-in-the-cerebral-cortex-a-review-i

\section{INTECH}

open science | open minds

\section{InTech Europe}

University Campus STeP Ri

Slavka Krautzeka 83/A

51000 Rijeka, Croatia

Phone: +385 (51) 770447

Fax: +385 (51) 686166

www.intechopen.com

\section{InTech China}

Unit 405, Office Block, Hotel Equatorial Shanghai

No.65, Yan An Road (West), Shanghai, 200040, China

中国上海市延安西路65号上海国际贵都大饭店办公楼 405 单元

Phone: +86-21-62489820

Fax: $+86-21-62489821$ 
(C) 2012 The Author(s). Licensee IntechOpen. This is an open access article distributed under the terms of the Creative Commons Attribution 3.0 License, which permits unrestricted use, distribution, and reproduction in any medium, provided the original work is properly cited. 